\section{Saúde de populações marginalizadas: desnutrição, anemia e enteroparasitoses em crianças de uma favela do "Movimento dos Sem Teto", Maceió, Alagoas}

\section{Health of marginalized populations: undernutrition, anemia and intestinal parasitic infections among children of a slum of the "Homeless Movement", Maceió, Alagoas}

Haroldo da Silva Ferreira 1 Monica Lopes de Assunção 2 Vivian Sarmento de Vasconcelos 3 Fabiana Palmeira de Melo 4 Cláudio Galindo de Oliveira 5 Tatiana de Oliveira Santos 6

1,6 Departamento de Nutrição da Universidade Federal de Alagoas. Campus A. C. Simões - BR 104 Norte - Km 96,7, Tabuleiro do Martins. Maceió, Alagoas, Brasil. CEP 57.072-970. Tel: (082) 214.1158, 214-1160. E mail: haroldo@ fapeal.br

2-5 Curso de graduação em Nutrição da Universidade Federal de Alagoas

\section{Resumo}

Objetivos: verificar a prevalência de desnutrição energético-protéica (DEP), anemia e enteroparasitoses em crianças de uma favela do "Movimento dos Sem Teto".

Métodos: estudo transversal envolvendo 137 crianças (6-60 meses). Como indicador da DEP aplicou-se o ponto de corte $z<-2$ aos indicadores peso para idade $(P / I)$, altura para idade (A/I) e peso para altura (P/A), relativamente ao padrão do NCHS. Para caracterização da anemia, usou-se método da Organização Mundial de Saúde, (haemoglobin colour scale). Concentração de hemoglobina $\leq 11 \mathrm{~g} /$ dl caracterizou o estado de anemia. Todas as crianças foram submetidas a exame parasitológico de fezes.

Resultados: as prevalências de deficits nutricionais para os indicadores A/I, P/I e P/A foram, respectivamente, 22,6\%, 16,1\% e 1,5\%. Quase todas as crianças apresentaram pelo menos um tipo de parasita $(83,2 \%)$. Destas, 50,9\% eram poliparasitadas. As associações mais freqüentes foram Ascaris + Trichuris (15,7\%) e Ascaris + Giardia (13\%). A anemia foi detectada em 96,4\% das crianças.

Conclusões: em virtude das altas prevalências de $D E P$, anemia e parasitoses e, considerando o efeito sinérgico entre desnutrição e infecções, conclui-se que o quadro de saúde verificado é extremamente precário, requerendo intervenção imediata a fim de garantir melhores condições de crescimento, desenvolvimento para essas crianças.

Palavras-chave Avaliação nutricional, Desnutrição protéico-energética, Anemia ferropriva, Enteropatias parasitárias 


\section{Introdução}

O estado nutricional pode ser definido como a condição de saúde e a constituição corporal do indivíduo, resultantes da ingestão e utilização biológica de nutrientes no decorrer de sua vida. ${ }^{1}$ Enquanto que a ingestão depende fortemente do poder aquisitivo das famílias, a utilização biológica está claramente associada a situações tais como as doenças infectoparasitárias. Tanto uma condição quanto a outra estão comprometidas em ambientes caracterizados pelo baixo nível socioeconômico. Assim posto, fica evidenciada a determinação social da desnutrição. Portanto, o estudo de sua prevalência constitui-se num excelente indicador de desenvolvimento social. 2

A Pesquisa Nacional sobre Saúde e Nutrição (PNSN) ${ }^{3}$ revelou que $30,7 \%$ das crianças brasileiras eram desnutridas, sendo que $5,1 \%$ em grau moderado ou grave de acordo com a classificação de Gomez et al. ${ }^{4}$ A prevalência de desnutrição (todas as formas) foi cerca de duas vezes e meia maior no Nordeste $(40,0 \%)$ do que a encontrada na população do Sul e Sudeste (20,6\%). Para os casos de desnutrição moderada e grave, a diferença foi ainda mais expressiva: $10,1 \%$ para o Nordeste e $2,4 \%$ para o Sul e Sudeste. ${ }^{3}$ Se considerarmos que no âmbito regional existem enormes distorções quanto à distribuição de renda e qualidade de vida da população, tais valores, quando apresentados para toda a Região ou mesmo para os Estados, apesar de serem por si só preocupantes, mascaram a gravidade com que o problema se manifesta em localidades mais restritas, onde a exclusão social se apresenta de forma mais contundente. Assim, a prevalência de desnutrição detectada pela PNSN para o estado de Alagoas foi bem inferior à que temos encontrado em comunidades periféricas desse Estado.5-8 Portanto, justifica-se a condução de inquéritos nessas comunidades notadamente submetidas aos fatores de risco nutricional.

Segundo Andrade et al., ${ }^{9}$ a desnutrição não se constitui em um fato isolado, mas no efeito da ação recíproca de fatores socioeconômicos, políticos, culturais e ambientais os quais atingem com maior intensidade as crianças pequenas que vivem em situações de pobreza extrema.

Esse fato é especialmente preocupante haja vista que os danos causados pela desnutrição são tão mais severos quanto mais rápido for o ritmo de crescimento e desenvolvimento. Existe um considerável corpo de evidências indicando que a desnutrição, em fases precoces da vida, promove redução da capacidade de realizar trabalho, maior vulnerabilidade às infecções, menor capacidade cognitiva, redução na capacidade de biotransformação metabólica, má-absorção intestinal de nutrientes, entre outros deficits. ${ }^{2}$

As anemias carenciais, ao lado da DEP, da hipovitaminose $\mathrm{A}$, do bócio endêmico e da cárie dental, representam os principais problemas nutricionais de importância clínico-epidemiológica em nosso País. 10 As anemias por deficiência de ferro se constituem em um dos principais problemas de saúde pública em âmbito mundial, atingindo sua máxima prevalência nos países subdesenvolvidos e/ou em desenvolvimento. Até predominam padrões dietéticos deficientes e fatores ambientais adversos que propiciam elevada prevalência de processos infecciosos e parasitários refletindo a situação econômica e social das populações carentes. 11

Além da inadequada ingestão de alimentos, as parasitoses intestinais têm sido consideradas importantes fatores na etiologia das anemias carenciais e da DEP. 12 Todavia, essa constatação aparentemente óbvia, não tem sido suportada por inúmeros trabalhos, sendo ponto de discórdia entre pesquisadores. ${ }^{13-15}$

O objetivo deste trabalho foi investigar a prevalência de enteroparasitoses, anemia e desnutrição energético protéica (DEP), em crianças pertencentes a população de uma favela da periferia do município de Maceió, bem como verificar a existência de associação entre essas variáveis.

\section{Métodos}

\section{População estudada}

O estudo foi realizado numa favela constituída há cerca de três anos por meio de uma ocupação organizada pela "União de Movimentos por Moradia em Alagoas", antigo "Movimento dos Sem Teto". Situase à margem da BR104, no bairro do Tabuleiro dos Martins, distante $19 \mathrm{~km}$ do centro de Maceió, Alagoas, Brasil.

Para identificação da população, realizou-se um censo onde foram cadastrados todos os domicílios e seus respectivos moradores. Segundo esse cadastro, 170 crianças na faixa etária de seis a 60 meses deveriam formar a casuística do estudo. No entanto, de 33 não se obtiveram todos os dados $(19,4 \%$ de perdas). O principal motivo de perda foi a ausência da criança no domicílio. Nesses casos, geralmente, a criança estava com familiares em outras localidades e, portanto, não submetidas aos mesmos fatores de risco daquelas que efetivamente residiam no local. Assim, foram avaliadas 137 crianças, sendo 50,3\% do sexo masculino e $49,7 \%$ do sexo feminino. 


\section{Exame coproparasitológico}

Os recipientes para coleta das fezes eram entregues nos respectivos domicílios, após explicação sobre o projeto e orientação de como proceder a coleta. As amostras eram recolhidas na manhã seguinte, acondicionadas em depósito resfriado e encaminhadas ao laboratório do Departamento de Patologia da Universidade Federal de Alagoas para análise imediata de ovos e larvas de helmintos e cistos de protozoários (método Hoffman, Pons e Janer). 16 Todas as amostras foram analisadas em triplicatas.

As crianças que apresentaram resultado negativo foram submetidas a um novo exame. Todas as crianças com resultado positivo eram encaminhadas ao Posto de Atendimento do Projeto, onde as mães recebiam orientação sobre a prevenção contra parasitoses, bem como a medicação específica para tratamento da criança.

\section{Avaliação antropométrica}

Os dados de massa corporal, estatura, sexo e idade foram coletados por estudantes do curso de nutrição previamente treinados na técnica antropométrica e sistematicamente acompanhados por um supervisor do trabalho de campo. As crianças foram pesadas em balança digital Filizolla ${ }^{\circledR}$ com capacidade para $150 \mathrm{~kg}$ e sensibilidade de $100 \mathrm{~g}$. A estatura das crianças menores de dois anos foi verificada estando as mesmas na posição de decúbito dorsal. Aquelas com idade superior a dois anos foram medidas descalças, na posição "em pé". Os estadiômetros (horizontal ou vertical) eram dotados de fita métrica inextensível com sensibilidade de $0,1 \mathrm{~cm}$.

Os indicadores utilizados para avaliação do estado nutricional foram altura para idade, peso para idade e peso para altura, sendo os resultados expressos em escores z em relação ao padrão antropométrico de referência proposto pelo National Center Health Statistics (NCHS). A condição de deficit foi definida pelo ponto de corte $\mathrm{z}<-2$ desvios-padrão.

\section{Diagnóstico de anemia}

O diagnóstico de anemia foi procedido por meio da utilização do "Haemoglobin colour scale" distribuído pela World Health Organization (WHO). 17

Através de punção digital coletava-se uma gota de sangue a qual era colocada em fita indicadora. A coloração obtida era comparada àquelas constantes de uma escala com diferentes intensidades de cores, representativas de valores de hemoglobina $(\mathrm{Hb})$ num intervalo de quatro a $14 \mathrm{~g} / \mathrm{dL}$.
A classificação recomendada pela WHO segundo Van den Broek, 17 quando da utilização desse recurso diagnóstico é a seguinte: (Hb/dL): não anêmico $(>11)$, anemia leve $(8,1-11,0)$, anemia moderada $(6,1-8,0)$ e anemia severa $(\leq 6,0)$.

\section{Dados socioeconômicos e ambientais}

Os dados ambientais foram obtidos por observação direta e os socioeconômicos através de entrevistas durante visitas domiciliares. As informações foram coletadas segundo um roteiro (formulário específico) estabelecido previamente em estudo piloto.

\section{Aspectos éticos}

O projeto foi aprovado pelo Comitê de Ética da Universidade Federal de Alagoas, em conformidade com as diretrizes da Comissão Nacional de Ética em Pesquisa (CONEP).

\section{Análise dos dados}

Os dados foram processados com auxílio do programa "Epi-info 6.0". Na análise estatística, utilizou-se o teste " $t$ " de Student para amostras independentes. Diferenças foram consideradas estatisticamente significantes quando $\mathrm{p}<0,05$.

\section{Resultados}

As condições de vida verificadas na localidade foram de extrema miséria. Todos os domicílios eram barracos feitos de caibros cobertos com plástico ou papelão. O piso não tinha revestimento. Não existia banheiro, de modo que os dejetos eram jogados a céu aberto, juntamente com o lixo em geral. A água era obtida da rede pública através de algumas torneiras colocadas em pontos estratégicos na favela e armazenada domesticamente em recipientes como tonéis, baldes e garrafas de refrigerante do tipo PET. A maioria das mães das crianças era analfabeta $(50,7 \%)$ e não estava inserida no mercado de trabalho. As que estavam, exerciam funções como as de empregada doméstica, lavadeira, etc. A renda familiar média foi de $\mathrm{R} \$ 120,00$. Como o número médio de habitantes por domicílio foi de quatro pessoas, a renda "per capita" mensal equivalia a $\mathrm{R} \$ 30,00$, valor esse inferior à quantia usualmente aceita como mínima suficiente para a manutenção de uma família: 0,25 salário-mínimo per capita 18 ou o equivalente a $\mathrm{R} \$ 45,00$. (Os cálculos foram procedidos com base no salário-mínimo vigente em novembro de 2001: 
$\mathrm{R} \$ 180,00 \cong \mathrm{US} \$ 72,00)$

$\mathrm{O}$ inquérito parasitológico revelou uma taxa de $83,2 \%$ de positividade entre as crianças estudadas. Os parasitas mais freqüentes foram o Ascaris lumbricoides $(47,4 \%)$, a Giardia lamblia $(32,1 \%)$ e o Trichuris trichiura $(21,2 \%)$, conforme ilustra a Figura 1 . O monoparasitismo foi encontrado em $49,1 \%$ das amostras analisadas, seguido do duplo parasitismo com $34,2 \%$ dos casos. As associações mais freqüentes foram entre Ascaris + Trichuris (15,7\%) e Ascaris + Giardia (13\%), uma vez que essas espécies foram, isoladamente, as mais prevalentes.
A Tabela 1 apresenta os resultados referentes ao estudo parasitológico, conforme as distintas faixas etárias. Verifica-se que à medida que aumenta a faixa etária, aumenta também a taxa de positividade. Assim, as crianças de seis a 12 meses foram as menos afetadas pelas parasitoses.

A Figura 2 ilustra os resultados referentes à prevalência de anemia. Verifica-se que $96,4 \%$ das crianças apresentavam baixos níveis sanguíneos de hemoglobina, ou seja, apenas cinco crianças não eram anêmicas.

\section{Figura 1}

Prevalência de enteroparasitoses entre crianças residentes em uma favela da "União de Movimentos por Moradia em Alagoas". Maceió, Brasil.

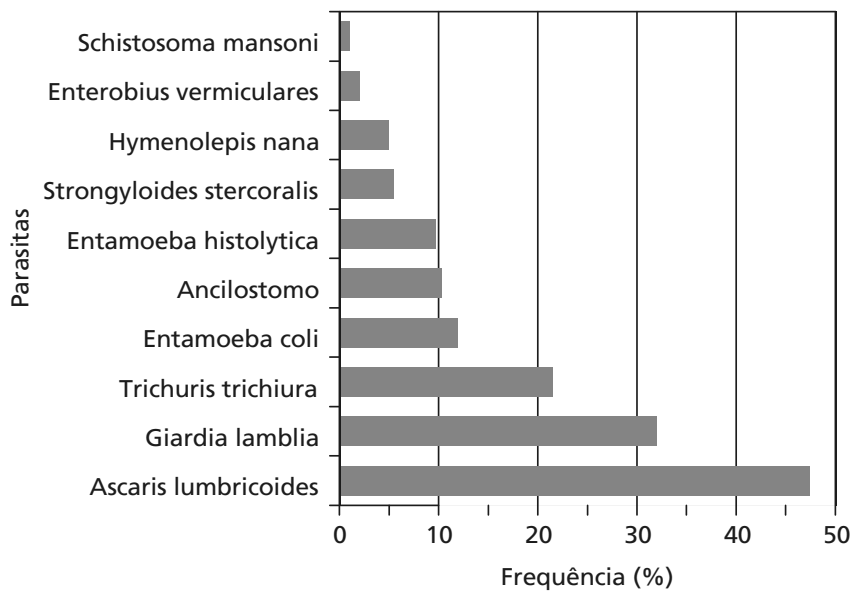


Caracterização das crianças segundo faixa etária e positividade para enteroparasitoses. Favela da "União de Movimentos por Moradia em Alagoas" Maceió, Brasil.

\begin{tabular}{|c|c|c|c|c|c|}
\hline \multirow{3}{*}{$\begin{array}{c}\text { Idade } \\
\text { (Meses) }\end{array}$} & \multicolumn{5}{|c|}{ Parasitológico de fezes } \\
\hline & \multicolumn{2}{|c|}{ Negativos } & \multicolumn{2}{|c|}{ Positivos } & \multirow{2}{*}{$\frac{\text { Total }}{n}$} \\
\hline & $\mathrm{n}$ & $\%$ & $\mathrm{n}$ & $\%$ & \\
\hline $6-12$ & 10 & 62,5 & 6 & 37,5 & 16 \\
\hline $12,1-24$ & 7 & 24,1 & 22 & 75,9 & 29 \\
\hline $24,1-48$ & 2 & 7,4 & 55 & 96,5 & 57 \\
\hline $48,1-60$ & 4 & 11,4 & 31 & 88,6 & 35 \\
\hline Total & 23 & 16,8 & 114 & 83,2 & 137 \\
\hline
\end{tabular}

Distribuição de crianças de seis a 60 meses conforme a classificação quanto à magnitude da anemia. Favela da "União de Movimentos por Moradia em Alagoas" Maceió, Brasil.

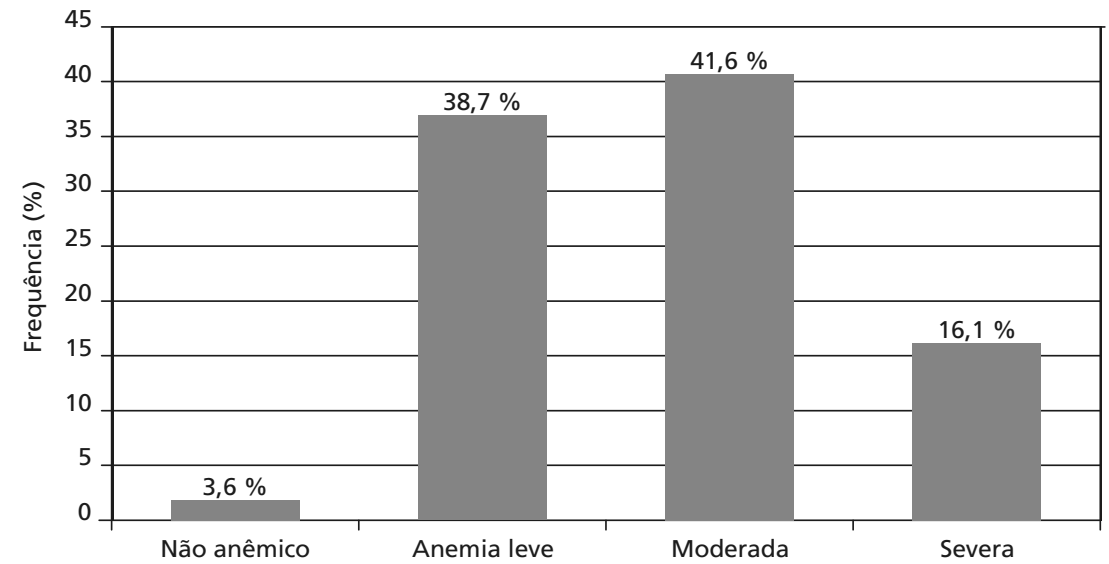

A classificação nutricional das crianças revelou uma prevalência de deficits para os indicadores altura para idade, peso para idade e peso para altura de, respectivamente $22,6 \%, 16,1 \%$ e $1,5 \%$ (Tabela 2 ).

A Tabela 3 apresenta a classificação antropométrica das crianças conforme as diferentes categorias em termos de parasitismo intestinal, enquanto a
Tabela 4, faz o mesmo, porém em relação à anemia. Aparentemente, o pior desempenho relativo ao crescimento, foi encontrado entre as crianças parasitadas por duas ou mais espécies. No entanto, a análise estatística indicou não haver diferença significante entre nenhuma das categorias apresentadas $(\mathrm{p}=0,45)$. 
Distribuição de crianças em diferentes faixas etárias com déficit nutricional. ( $<<-2 \mathrm{dp}$ da mediana do padrão do NCHS), de acordo com os indicadores antropométricos. Favela da "União de Movimentos por Moradia em Alagoas". Maceió, Brasil.

\begin{tabular}{|c|c|c|c|c|c|c|c|}
\hline \multirow{2}{*}{ Faixas etárias (meses) } & \multirow{2}{*}{$\mathbf{n}$} & \multicolumn{2}{|c|}{$P / I$} & \multicolumn{2}{|c|}{$A / I$} & \multicolumn{2}{|c|}{ P/A } \\
\hline & & $\mathrm{n}$ & $\%$ & $\mathrm{n}$ & $\%$ & $\mathrm{n}$ & $\%$ \\
\hline $6,1-12$ & 16 & 3 & 18,8 & 1 & 6,3 & 1 & 6,3 \\
\hline $12,1-24$ & 27 & 8 & 29,6 & 10 & 37,0 & 1 & 3,7 \\
\hline $24,1-60$ & 94 & 11 & 11,7 & 20 & 21,3 & 0 & 0,0 \\
\hline Total & 137 & 22 & 16,1 & 31 & 22,6 & 2 & 1,5 \\
\hline
\end{tabular}

$\mathrm{P} / \mathrm{I}=$ peso para idade, $\mathrm{A} / \mathrm{I}=$ altura para idade, $\mathrm{P} / \mathrm{A}=$ peso para altura

\section{Tabela 3}

Escore $\mathrm{z}$ (média $\pm \mathrm{dp}$ ) para três indicadores antropométricos, segundo categorias relativas ao enteroparasitismo. Crianças de seis a 60 meses residentes na favela da "União de Movimentos por Moradia em Alagoas". Maceió, Brasil.

\begin{tabular}{|c|c|c|c|c|c|}
\hline \multirow[b]{2}{*}{ Indicador } & \multirow{2}{*}{$\begin{array}{c}\text { Negativos } \\
n=23\end{array}$} & \multirow{2}{*}{$\begin{array}{c}\text { Positivos } \\
\mathrm{n}=114\end{array}$} & \multicolumn{3}{|c|}{ Número de espécies por hospedeiro } \\
\hline & & & $\begin{array}{c}1 \\
n=56\end{array}$ & $\begin{array}{c}2 \\
n=39\end{array}$ & $\begin{array}{l}3 \text { ou }+ \\
n=19\end{array}$ \\
\hline & $-1,00 \pm 0,9$ & $-1,26 \pm 1,2$ & $-1,26 \pm 1,2$ & $-1,26 \pm 1,4$ & $-1,26 \pm 1,2$ \\
\hline \multirow[t]{2}{*}{$A / I$} & & $p=0,34$ & & & \\
\hline & $-0,66 \pm 1,1$ & $-0,88 \pm 1,1$ & $-0,90 \pm 1,1$ & $-0,97 \pm 1,1$ & $-0,63 \pm 1,0$ \\
\hline \multirow[t]{2}{*}{$\mathrm{P} / \mathrm{I}$} & & $p=0,39$ & & & \\
\hline & $-0,01 \pm 1,1$ & $-0,10 \pm 0,8$ & $-0,13 \pm 0,8$ & $-0,23 \pm 0,8$ & $0,22 \pm 1,0$ \\
\hline P/A & & $p=0,66$ & & & \\
\hline
\end{tabular}

Escore z $(X \pm d p)$ para três indicadores antropométricos, segundo categorias relativas à anemia. Crianças de seis a 60 meses residentes na favela da "União de Movimentos por Moradia em Alagoas". Maceió, Brasil.

\begin{tabular}{|c|c|c|c|c|}
\hline \multirow{2}{*}{ Indicador } & \multirow{2}{*}{$\begin{array}{c}\text { Não anêmico } \\
n=5\end{array}$} & \multicolumn{3}{|c|}{ Anemia } \\
\hline & & $\begin{array}{l}\text { Leve } \\
n=53\end{array}$ & $\begin{array}{c}\text { Moderada } \\
n=57\end{array}$ & $\begin{array}{l}\text { Severa } \\
n=22\end{array}$ \\
\hline$A / I$ & $-1,35 \pm 0,86$ & $-1,27 \pm 0,97$ & $-1,14 \pm 1,44$ & $-1,26 \pm 1,14$ \\
\hline $\mathrm{P} / \mathrm{I}$ & $-1,36 \pm 0,87$ & $-0,95 \pm 0,91$ & $-0,73 \pm 1,26$ & $-0,78 \pm 1,13$ \\
\hline P/A & $-0,38 \pm 0,60$ & $-0,19 \pm 0,86$ & $-0,01 \pm 0,90$ & $0,03 \pm 1,05$ \\
\hline
\end{tabular}




\section{Discussão}

A prevalência de enteroparasitoses foi superior a $83 \%$, sendo que as crianças com mais de dois anos de idade eram quase todas parasitadas. Mesmo entre as menores de um ano, apesar da menor magnitude, essa ocorrência foi também elevada $(37,5 \%)$. CostaMacedo et al. 19 encontraram uma prevalência de $8,3 \%$ de enteroparasitoses em crianças menores de um ano de uma área periférica do município de Duque de Caxias, Rio de Janeiro. Outros autores também têm encontrado prevalências crescentes de parasitoses, conforme a faixa etária.20-22 A partir do segundo semestre de vida inicia-se uma etapa do desenvolvimento que permite à criança maior mobilidade no ambiente, aumentando dessa forma as chances de contaminação. ${ }^{21}$ Considerando, ainda, a extrema precariedade ambiental em que vivem as crianças estudadas, o desmame que ocorre nessa fase da vida e a paulatina introdução de novos alimentos, oferecidos, quase sempre, em condições higiênicas insatisfatórias, contribuem para o aumento da incidência das parasitoses

Vários fatores ambientais facilitadores da infecção enteroparasitária estavam claramente presentes no âmbito da comunidade estudada, entre esses a ausência de água de boa qualidade e de fossas, dejetos e detritos a céu aberto, solo úmido, altas temperaturas, grande proliferação de insetos e dificuldade de acesso aos serviços públicos de saúde.

Os parasitas mais freqüentemente encontrados em diversos estudos são o Ascaris lumbricoides, o Trichuris trichiura e a Giardia lamblia 15,20,23 coincidindo com os nossos achados. Devido à alta prevalência e a freqüência de reinfecções, a ascaridíase e a tricuríase representam, de acordo com Heyneman, 24 um importante problema de saúde pública, em consequiência da desnutrição e do atraso no crescimento que podem ocasionar. A giardíase pode apresentar-se de forma aguda, principalmente como diarréia, subaguda ou assintomática. Mesmo entre os assintomáticos, obtém-se freqüentemente evidência de má-absorção intestinal, prejudicando assim o estado nutricional.25

Vale ressaltar que o inquérito detectou um caso de esquistossomose mansônica. Diante da importância epidemiológica desse fato, realizou-se a uma investigação criteriosa a respeito. Era uma menina de quatro anos procedente há seis meses da área rural do município de São José da Lage, reconhecidamente área endêmica dessa parasitose. No mesmo domicílio havia mais 10 pessoas cujos exames de fezes foram todos positivos para S. mansoni. Não foi constatada a presença do hospedeiro intermediário
(Biomphalaria glabrata ou straminea) em possíveis criadouros nos arredores da favela. A família foi encaminhada para a Fundação Nacional de Saúde (FUNASA) a fim de receber tratamento específico.

A quase totalidade das crianças estudadas apresentava algum grau de anemia. Saloojee e Pettifor26 relatam que em países subdesenvolvidos, metade dos casos de anemia existentes em crianças e gestantes, principais grupos vulneráveis, é decorrente da deficiência de ferro (anemia ferropriva). Admite-se que a ocorrência de anemia ferropriva na infância seja proveniente da combinação de necessidades excepcionalmente elevadas de ferro, impostas pelo crescimento, dietas pobres nesse mineral e da alta frequiência de enfermidades infecto-parasitárias. 27

A prevalência de anemia no Brasil em crianças menores de cinco anos varia de 25 a $68 \% .28$ Assim, a prevalência ora divulgada excede às existentes em qualquer outro contexto, evidenciando, mais uma vez, o papel preponderante da condição socioeconômica sobre as enfermidades carenciais.

Independentemente das causas que determinam o estado anêmico, associam-se ao mesmo graves prejuízos para o desenvolvimento cognitivo e motor da criança e para o seu futuro aproveitamento escolar, do que resulta a grande importância que se deve dar ao controle da anemia na infância. 29

Quanto ao estado nutricional, a maior freqüência de deficits, dentre os três indicadores estudados, foi observada para a relação estatura para idade $(22,6 \%)$. Utilizando um ponto de corte menos rigoroso ( $\mathrm{z}<-1 \mathrm{dp}$ ), não adequado para diagnosticar desnutrição, porém de maior utilidade para indicar situação de risco (triagem), 2 essa prevalência sobe para $65 \%$. (Na população de referência (NCHS), o número de indivíduos abaixo desse ponto de corte é de apenas 16\%). Essa é uma característica de populações submetidas à desnutrição crônica, onde a inadequada ingestão e/ou utilização biológica de nutrientes, compromete o crescimento e o desenvolvimento da criança.30 A baixa prevalência de deficits para a relação peso para altura justifica-se pela adequação da massa corporal à menor estatura apresentada pela criança para a respectiva faixa etária. Assim, na população estudada, os deficits de peso para idade são explicados pela menor estatura dos indivíduos.

A prevalência de enteroparasitoses, bem como a de anemia, foi extremamente alta, atingindo, praticamente, todas as crianças avaliadas, o que dificultou o estudo da associação entre essas condições e os indicadores antropométricos em virtude de que o grupo "não doente" ficou bastante restrito. A esse respeito, a literatura não tem convergido no sentido de es- 
clarecer o problema. Tsuyuoka et al. 31 verificaram que crianças com enteroparasitoses apresentavam valores de peso para altura inferiores aos daquelas com resultados negativos. No entanto, outros autores 13-15,22 não verificaram associação entre a infecção enteroparasitária e o estado nutricional.

Tomkins 32 relata que a Giardia lamblia e o Ascaris lumbricoides, parasitas mais freqüentes em nosso estudo, podem interferir no crescimento se estiverem presentes em grande número ou se a ingestão alimentar e as condições gerais de saúde do hospedeiro forem precárias. Correia e McAuliffe, 25 relatam estudos que demonstraram má-absorção intestinal em crianças infectadas por Giardia lamblia ou Ascaris lumbricoides, com prejuízos ao seu estado nutricional. Ferreira et al.,33 em estudo experimental com camundongos, verificaram que a esquistossomose não afetava a absorção intestinal de proteínas quando os animais recebiam dieta balanceada, porém agravava a má-absorção presente nos animais desnutridos pelo consumo de uma dieta multideficiente.

Além da possível má-absorção induzida por parasitas intestinais, outros mecanismos poderiam oca-

\section{Agradecimentos}

Os autores agradecem aos técnicos da Fundação Nacional de Saúde Antônio Soares S. Sobrinho e João Florentino dos Santos, pela realização dos exames parasitológicos; aos estagiários do Laboratório de Nutrição Básica e Aplicada da Universidade Federal de Alagoas, pela colaboração na coleta de dados; aos Professores Carlos Gonçalves de Oliveira e Célia

\section{Referências}

1. WHO (World Health Organization), United Nations Protein Advisory Group. Anthropometry in nutritional surveillance: an overview. Bull World Health Organ 1976; 6: 211.

2. Ferreira HS. Desnutrição: magnitude, significado social e possibilidade de prevenção. Maceió: Universidade Federal de Alagoas; 2000.

3. INAN (Instituto Nacional de Alimentação e Nutrição). Pesquisa Nacional sobre Saúde e Nutrição: resultados preliminares. Brasília, DF: Ministério da Saúde; 1990.

4. Gomez F, Galvan GR, Frenk S, Munhões JC, Chaves R, Vasques J. Mortality in second and third degree malnutrition. J Trop Paediatr 1956; 2: 77-83. sionar alterações no estado nutricional. Entre esses se incluem a anorexia, a atrofia de vilosidades, as alterações enzimáticas (diminuição da lactase e peptidases presentes nos vilos), a desconjugação dos ácidos biliares (limitando a produção de micelas), a competição por nutrientes e o aumento das necessidades energéticas. 32

O perfil ora apresentado corrobora os argumentos de Andrade et al.,9 de que a desnutrição é determinada pelo efeito da ação recíproca de diversos fatores. Na população estudada, a interação entre a miséria, o meio ambiente inóspito e a falta de atenção à saúde, gerando fome e infecções constantes, são responsáveis pela situação caótica prevalecente. Em virtude das altas prevalências de desnutrição, anemia e parasitoses intestinais encontradas e, considerando o efeito sinérgico entre desnutrição e infecções, conclui-se que o quadro de saúde verificado é extremamente precário, requerendo intervenção imediata a fim de garantir melhores condições de crescimento, desenvolvimento e qualidade de vida a essas crianças.

Dias dos Santos pela revisão crítica do manuscrito; à Secretaria de Saúde de Alagoas e à Fundação de Amparo à Pesquisa do Estado de Alagoas (FAPEAL) pelo apoio financeiro e, em especial, às lideranças da "União de Movimentos por Moradia em Alagoas" e a todas as mães e crianças que, gentilmente, se submeteram a este trabalho.

5. Ferreira HS, Levino J. Obtenção de amostras representativas através das campanhas nacionais de vacinação: inquérito antropométrico entre pré-escolares de Maceió - AL. In: Anais do XXX Congresso Brasileiro de Pediatria; 5-10 out 1997; Rio de Janeiro, RJ, Brasil. Rio de Janeiro: Sociedade Brasileira de Pediatria; 1997.

6. Ferreira HS, Albuquerque MFM, Ataíde TR, Morais MGC, Mendes MCR, Siqueira TCA, Silva GJ. Estado nutricional de crianças menores de 10 anos residentes em invasão do "Movimento dos Sem Terra", Porto Calvo, Alagoas. Cad Saúde Pública 1997; 13: 137-9.

7. Ferreira HS, Assunção ML, França AOS, Moura FA. Sobrevivendo no lixo: perfil antropométrico de crianças 
menores de 10 anos residentes na "Favela do Lixão", Maceió - Alagoas. In: Anais do V Congresso Brasileiro da Sociedade Brasileira de Alimentação e Nutrição; 5-8 dez 1999; São Paulo, SP, Brasil. São Paulo: Sociedade Brasileira de Alimentação e Nutrição; 1999.

8. Florêncio TMMT, Ferreira HS, Cavalcante JC, França APT, Sawaya AL. Obesity and undernutrition in a very low income population in the city of Maceió, Northeastern Brazil. Br J Nutr 2001; 86: 277-84.

9. Andrade SLLS, Romani SAM, Andrada LAC, Simões R. Avaliação do estado nutricional de escolares do distrito de Poço Comprido - Zona da Mata - PE. In: Anais do XIV Congresso Brasileiro de Nutrição; 22-26 ago 1996; Belo Horizonte, Minas Gerais, Brasil. Belo Horizonte: Associação Brasileira de Nutrição; 1996.

10. Batista Filho M. Saúde e nutrição. In: Rouquayrol MZ, editor. Epidemiologia \& Saúde. 4. ed. Rio de Janeiro: MEDSI; 1994. p. 365-81.

11. Romani SAM, Lira PIC, Batista Filho M, Siqueira LAS, Freitas CLC. Anemias em pré-escolares: diagnóstico, tratamento e avaliação, Recife, PE, Brasil. Arch Latinoam Nutr 1991; 41: 159-208.

12. Mello DA, Pripas S, Fucci M, Santoro MC, Pedrazzani ES. Helmintoses intestinais no Subdistrito de Santa Eudóxia (Município de São Carlos-SP). I. Conhecimentos, atitudes e percepção da população sobre helmintos e helmintoses intestinais. Rev Saúde Pública 1988; 22. 140-9.

13. Jorge João WS. Prevalência de desnutrição em crianças menores de 6 anos de idade atendidas no serviço ambulatorial da Santa Casa do Pará. Hiléia Med 1983; 4: 3342.

14. Sigulem DM. Anemia nutricional e parasitose intestinal em menores de 5 anos. Rev Paul Med 1985; 103: 308-12.

15. Pedrazzani ES, Mello DA, Pripas S, Fucci M, Barbosa CAA, Santoo, MCM. Helmintoses intestinais. II. Prevalência e correlação com renda, tamanho da família, anemia e estado nutricional. Rev Saúde Pública 1988; 22: 384-9.

16. Hoffman WA, Pons JA, Janer JL. The sedimentation concentration method in schistosomiasis mansoni. J Public Health Trop Med 1934; 9: 283-91.

17. Van den Broek NR, Ntonya C, Mhango E, White SA. Diagnosing anaemia in pregnancy in rural clinics: assessing the potential of the Haemoglobin Colour Scale. Bull World Health Organ 1999; 77: 15-21.

18. Hoffmann R. Pobreza, insegurança alimentar e desnutrição no Brasil. Est Avançados 1995; 9: 159-72.

19. Costa-Macedo LM, Costa MCE, Almeida LM. Parasitismo por Ascaris lumbricoides em crianças menores de dois anos: estudo populacional em comunidade do Estado do Rio de Janeiro. Cad Saúde Pública 1999; 15: 173-8.
20. Costa-Macedo LM, Machado-Silva JR, Rodrigues-Silva R, Oliveira LM, Vianna MSR. Enteroparasitoses em pré-escolares de comunidades favelizadas da cidade do Rio de Janeiro, Brasil. Cad Saúde Pública 1998; 14: 851-6.

21. Monteiro CA, Chieffi PP, Benício MHA, Dias RMS, Torres DMAGV, Mangini ACS. Estudo das condições de saúde das crianças do Município de São Paulo (Brasil), 1984/1985. VII. Parasitoses intestinais. Rev Saúde Pública $1998 ; 22: 8-15$.

22. Ferreira MU, Ferreira CS, Monteiro CA. Tendência secular das parasitoses intestinais na infância na cidade de São Paulo (1984-1996). Rev Saúde Pública 2000; 34: 73-82.

23. Machado RC, Marcari EL, Cristante SFV, Carareto CMA Giardíase e helmintíases em crianças de creches e escolas de $1^{\circ}$ e $2^{\circ}$ graus (públicas e privadas) da cidade de Mirassol (SP, Brasil). Rev Soc Bras Med Trop 1999; 32: 697-704

24. Heyneman D. Parasitologia médica. In: Jawetz E, Melnick JL, Adelberg EA. Microbiologia médica. 20. ed. Rio de Janeiro: Guanabara-Koogan; 1998. p. 444-62.

25. Correia LL, McAuliffe JF. Saúde materno infantil. In: Rouquayrol MZ. Epidemiologia \& Saúde. 4. ed. Rio de Janeiro: Medsi; 1994. p. 315-42.

26. Saloojee H, Pettifor JM. Iron deficiency and impaired child development. Br J Nutr 2001; 323: 1377-8.

27. Monteiro CA, Szarfarc SC, Mondini L. Tendência secular da anemia na infância na cidade de São Paulo (1984 1996). Rev Saúde Pública 2000; 34: 62-72.

28. Brunken GS, Guimarães LV, Fisberg M. Anemia em crianças menores de 3 anos que freqüentam creches públicas em período integral. J Pediatr (Rio de Janeiro) 2002; 77: $50-6$

29. Lajolo FM, Tirapegui J. Proteínas e aminoácidos. In: Dutra de Oliveira JE, Marchini JS. Ciências nutricionais. São Paulo: Sarvier; 1998. p. 41- 65.

30. Waterlow JC. Metabolic adaptation to low intakes of energy and protein. Ann Rev Nutr 1986; 6: 495-526.

31. Tsuyuoka R, Bailey JW, Guimarães AMDN, Gurgel RQ, Cuevas LE. Anemia and intestinal parasitic infections in primary school students in Aracaju, Sergipe, Brazil. Cad Saúde Pública 1999; 15: 413-21.

32. Tomkins A. Parasitas intestinais. In: Walker-Smith JA, Mcneish AS. Diarréia e desnutrição na infância. Rio de Janeiro: Revinter; 1989. p. 71-90.

33. Ferreira HS, Coutinho EM, Teodósio NR, Cavalcanti CL, Samico MJ. Intestinal protein absorption in malnourished mice with acute schistosomiasis mansoni. Mem Inst Oswaldo Cruz 1993; 88: 581-7.

Recebido para publicação em 29 de maio de 2002 Versão final reapresentada em 2 de julho de 2002 Aprovado em 2 de agosto de 2002 